\title{
Exploration on Application of "people-oriented" on Higher Education Reform
}

\author{
Hui Cheng ${ }^{1}$, Ming-Chen Wei ${ }^{2}$ \\ ${ }^{1)}$ Department of Foreign Language, Weifang College, Weifang, Shandong, China \\ ${ }^{2)}$ Department of Teachers' Education, Weifang College, Weifang, Shandong, China
}

\begin{abstract}
People-oriented" is the nature of Scientific Outlook on Development, application of the "people-oriented" on higher education reform is much more essential, since universities are the important places of cultivating talents. On the whole, the paper is made up of two parts. Systematically, part one makes theoretical explanation as well as practical application of "people-oriented". Part two explores application of "people-oriented" on higher education reform from three aspects: university talent cultivation modes, classroom teaching and student academic assessment..
\end{abstract}

Keywords - enrolment system, comparison, enlightenments

\section{“以人为本”理念在高校教育教学改革中应用初探}

\author{
程 辉 $^{1}$ 魏晨明 ${ }^{2}$ \\ 1) 淮坊学院外国语学院, 潍坊, 山东, 中国 \\ 2) 潍坊学院教师教育学院, 潍坊, 山东, 中国
}

摘 要 以人为本是科学发展观的核心, 高校是培养人才的重要阵地, 高校教育教学改革坚持以人为本显得更加重要。本文在对 以人为本理念进行理论阐释的同时, 主要从高校人才培养模式、课堂教学和学生成绩的考核和评价等三个方面如何贯彻以人为本的理 念谈些粗浅看法，敬请同行指正。

关键词 以人为本; 人才培养模式; 课堂教学; 学生成绩考核与评价

“以人为本”的理念是, 是人类教育理念的重大进步。 从东西方教育发展史来看, “以人为本”的提出, 实际上确 立了人在教育活动中的主体地位, 把教育活动的过程、技 术和目标，都集中到了人的发展这个根本问题上。特别是， 在当代中国, 随着中国共产党将 “以人为本”确立为科学发 展观的核心, 并将科学发展观纳入指导思想的体系, 这标 志着中共指导思想的一个重大飞跃。同时, “以人为本”的 指导思想的确立, 也为中国高校的教学改革中提供了根本 的方向。

\section{1. “以人为本”理念阐释}

要真正把“以人为本” 贯彻到高校教学活动中, 进一步 推进教学改革, 首先需要我们破解三个命题: 一是“以什么 人为本”; 二是“以人的什么为本”; 三是如何才能做到“以
人为本”。

1.1 “以什么人为本”

对于整个社会来讲, “人”就是指所有现实的人，即社 会全体成员，在中国特色社会主义制度下其主体就是“人 民”。这里的“人民”主要是一个政治概念，具体说就是指当 今社会中一切遵纪守法的公民。当然, 对违法者的制裁也 应该贯彻“以人为本”, 但在性质和内容上是不一样的。

对于高校来说, 以人为本的“人” 是指全体教职员工和 全体学生。具体可以分成三种: 第一种人, 是全体在校学 生, 这是高校一切工作的出发点和落脚点, 高校的工作就 是真正把学生培养成合格的中国特色社会主义建设者。所 以, 毛泽东就说过: “学校的校长、教员是为学生服务的, 不是学生为校长、教员服务的。” 1 第二种人, 是一线教学 
和管理的教职员工, 还有一种, 是教学管理层, 主要是管 理及教辅部门的教职员工。

为什么要做这样的区分? 首先, 从教育和教学过程的 规律来看, 教师和学生是教育教学的密不可分的两个主体, 教师是教学活动的一个主体, 学生是承受教育教学活动的 对象; 第二, 从教育管理学的角度来看, 高校管理者对教 育教学质量起着关键的主导作用, 他们在一定程度上决定 了一线教师的职称评定、资源分配和关系调动等。第三, 学生、一线教职工、教学管理层, 这三个方面的关系, 决 定了一个高校的教育水平和教学质量, 也决定了这个高校 的未来发展。

\section{2 “以人的什么为本”}

对于整个社会来讲, 贯彻“以人为本”原则, 就是要满 足人民群众日益增长的物质和文化需要, 促进人的全面发 展, 最大限度的激发人的潜能和实现人的价值。马克思指 出: “任何人的职责、使命、任务就是全面地发展自己的一 切能力。” 2 作为高校来讲, 一方面要最大限度调动一切教 育教学资源, 不断激发学生学习的主动性, 只有心思在学 习上才能谈得上学习进步, 将来工作中才能出彩。另一方 面, 同时也要尽可能地激发全体教职员工的主观能动性, 让每一位教师都能在教育教学活动中, 真正实现自身的价 值和目标。

恩格斯强调, “每一个人都无可争辩地有权全面发展自 己的才能”。3 从这一点上来说, 在高校教育教学活动中贯 彻以人为本, 就是要实现学生、教师、高校管理者的共同 的全面发展。因为, 如果没有这三者的共同进步, 共同提 高, 就不可能实现学生的全面发展, 不可能实现教师的全 面发展, 也不可能实现教学管理者的全面发展。

\section{3 是如何才能做到“以人为本”}

学校教育自身而言, 必须创新培训、管理、评价三种 机制, 真正实现以人为本。在培训内容上, 以师德为重; 培 训形式上, 以校本培训为主; 而培训效果的运用上, 与考核 评价挂钩。在管理机制上, 牢固树立情感、制度、成功管 理的理念。在评价机制上, 即要重视教师的共性又要重视 个体差异, 建立促进教师发展的多元化评价。

\section{2. 处理好“以人为本”与因材施教的关系}

众所周知, 每一个人都有自己的天赋, 都有自己的特 点。“以人为本”是指让每一个学生都有接受教育、发挥自 己潜能的机会。“在人人都享有同等受教育机会的基础上, 使每个人都能根据自己的爱好、才能和智慧的不同, 来获
得他们的最高的发展”。4 当然, 现代教育一个重要的特点, 就是往往是追求标准化的系统培养, 这在一定程度上容易 抹杀学生的天赋。因此, 我们必须认真总结经验, 切实发 掘每一个学生的潜能, 这才是真正的“以人为本”。

\section{3. “以人为本”理念在高校教学改革中的应用}

在高校教学改革中, 要把以人为本贯彻到高校的教学 活动、社团活动、管理活动等各个方面。

\section{1 以人为本, 构建和谐课堂}

课堂教学是教学工作最基本的形式, 努力做到启发式 教学和理论联系实际这两方面, 从而实现活力和和谐课堂。

一是大力提倡启发式教学, 多和学生互动, 给学生鼓 励, 让他们勇于表现自己的观点。在课堂教学中注意把握 好学生的基础差异, 对于基础较差的, 就试着抛出相对简 单、以期鼓励下次进步的题目; 而对于基础好, 又想展示 的学生也要找到合适的机会让他们都能较好保持好的学习 状态。

二是大力倡导理论联系实际 (学生的生活实际、思想 实际和社会实际) 的教学方式, 下面就如何在教学中将课 文的主题思想与学生的思想实际相结合, 进而实现学生在 掌握语言知识的同时在不知不觉中提高思想意识。实际每 个学期的八个单元的文章都是和日常生活及学生的思想息 息相关的。在刚刚进行的模块中就是讨论一个非常现实的 社会矛盾的, 就是熟练技术工人短缺而大量的大学生又失 业之间的巨大差距。在教学中就引导学生对自己的未来人 生做好规划。

以人为本, 把课堂当做实施教育教学改革的主阵地, 进而构建和谐校园。

3.2 以人为本, 构建科学合理的学生学业成绩考核评价体 系

以笔者的大学英语教学为例: 一是变原来的一个层次, 为多个层次。由一到多是较为科学化地转变。原来的大学 新生都是统一的教材, 一份试题。这样的问题非常多, 包 括高考英语成绩 140 分的学生和 40 分的学生又都处在了同 一条起跑线。这样, 水平差距巨大导致了部分字母认不全 的英语低分学生彻底丧失信心而破罐子破摔; 高分的学生 又因为沾沾自喜而不屑于课上听讲, 这种由于水平差距悬 殊而导致的教师无法正常授课。全英文的授课无法进行, 而全汉语授课又失去了语言教学的实际环境。在新的成绩 考核评价体系中就很好避免了这个矛盾。将全部的大一新 生分成多个层次, 有音体美等艺术生、专科生; 第二个层 
次是普通本科生的慢班; 最高层次的是普通本科生的快班。 其中快、慢班的分班是在入学后的统一测试中的成绩划分 而来的。分班结束后就是教学进度的差距了, 对于第一个 层次的学生学习的是大学预科的教材, 其难度相当于高中 水平。而第二个层次的学生是占大多数比例的, 是按照正 常的大学英语教学进度, 在第四个学期期参加大学英语四 级考试, 而最高层次的学生是在第二个学期就有资格参加 四级考试了, 到第四学期的时候, 大部分的学生就可以参 加大学英语的六级考试并取得不错的成绩了。

二是学生英语学业成绩考核评价由原来的结果性评价 变成了现在的过程性评价。原来的一学期一张试卷, 就是 结果性评价, 它有很多弊端。现在的过程性评价就是指, 学生的学业成绩组成分成多个模块, 基本原则是期末的试 卷占全部成绩的百分之四十; 其它的称为平日成绩。而平 日成绩的组成更加复杂, 包括课堂表现的百分之三十, 口 语测试的百分之二十, 网上自主学习系统的百分之十, 这 些合并成学生百分制的最终成绩。由结果性评价变成过程 性评价的好处日益凸显。

首先是, 教师可以很好地利用课堂时间来调动学生的 学习积极性, 因为老师有很大的自主权, 并通过对学生的 出勤情况来了解学生的学习。课堂表现的这百分之三十, 很明显地遏制了学生旷课现象, 毕竟学习较差的学生希望 通过满出勤来拿到稍高的分数。教师还可以通过课堂的互 动来实现提高课堂学习效率的目的。在课堂上如果积极主 动互动、并且较好得回答问题的学生都可以拿到较好的课 堂表现, 甚至是满分。其次, 口语测试也是对于语言学习 评价至关重要的, 只有做到听说测试, 才能算得是较为科 学的语言测试。再有, 课下的自主学习, 学生只有在课下 登录、学习、提交了作业, 才能拿到这总评的百分之十的 成绩。这样就很好地做到了课上与课下相结合, 教授与自 学相结合的目的。

总之, 由于英语学业成绩考核评价的改革, 我们看到 了可喜的发展和进步, 学生和老师的状态都得到了明显地
提升, 这些都与 “以人为本” 的理念在教学成绩评价上的贯 彻和应用分不开。也可见科学合理的学业成绩考核评价是 多么重要, 有极其重要的意义。

3.3 以人为本, 进一步推进高校教师和管理者的自身发展 教育是一门艺术, 是教师把社会生产、社会生活的经 验、知识和技能, 系统地有计划、有步骤地传授给年青一 代的过程。教育特别是高等教育有着自己特殊的规律。

从目前看, 高校贯彻“以人为本”, 就要逐步建立和完 善中青年教师的培训进修计划, 有针对性地制定人才发展 方案, 优化教师队伍, 提高教学水平。要积极开展教学评 估, 建立科学合理的教训评估体系, 充分调动教师的积极 性和创造性。要创新高校管理方式方法, 敢于打破各种陈 旧的条条框框, 逐步建立以服务学生和教师为中心的高校 管理体系。

作为高校的教师和管理者, 一定要不断丰富自己的知 识素养, 不断提高自身的思想理论水平, 遵循教育规律和 教育管理, 锤炼教学艺术, 在教育教学活动中大胆改革创 新, 探索出具有中国特色的高等教育发展之路。

\section{参考文献(References)}

[1] Education Thoughts of Zedong Mao, Beijing: People's Education Press, pp. 289,1992.

[2] Central Compilation and Translation Bureau, Marx and Engels, Selected Works, vol. 1, Beijing: People's Publishing House, pp. 330,1960.

[3] Central Compilation and Translation Bureau, Marx and Engels, Selected Works, vol.1, Beijing: People's Publishing House, pp.614,1957.

[4] F.Bolson, Gemany History of Education, Dachun Teng, Dasheng Teng, translated, Beijing: People's Education Press, pp. 200,1987. 